art. It was a one man compilation. It was superseded in 1923 by the comprehensive Marine Products of Commerce produced in the United States by D. K. Tressler with assistance from seventeen collaborators. This was more authoritative than Simmonds's book but covered much the same fisheries, including whales and other marine mammals, and industrial products from seaweeds. The most striking advances were in the chapters covoring methods for fish preservation and the proparation of fish meal and fertilizers.

At tho end of another half century this Encyclopedia of Marine Resources is as much larger than its predecessor as that was larger than Simmonds's book. The editor has assembled a team of 152 contributors, the majority being fellow Americans but including authorities from all leading maritime nations, including Britain. Starting with abalone and finishing with whales and whaling, there seems to be nothing appertaining to the resources of the sea and to the inereasingly sophisticated methods of detection, collection and processing which is not covered.

The fishing industries of all maritime nations, including those of the US Trust Territories in the Pacific, are covered, as are turtles, whaling and the shell fisheries-bivalve, gastropod and crustacean. All major commercial fishes and the more important invertebrates and seaweeds are separately considered. There are also admirable sections on marine ecology in all aspects from plankton to benthos, including a contribution on the interstitial fauna and one on the productivity of marine communities. The abyssal zone no less than the Peru Current is covered. Marine fungi and dinoflagellates are both discussed.

There are sections on marine biotoxins and on the toxicology of marine animals, and on the sea lamprey with a description of its invasion of the Great Lakes and eventual control. In a section on the Maine marine worm fishery (for the annelid bloodworm, Glycera dibranciata) we learn that this is "probably the most valuable, regularly harvested marine animal in the world per unit of weight". Included among the methods for increasing fishing yield is tho construction of artificial reefs in which crayfish and certain fishes congregate.

The major chemical products are considered and also, under desalination, the supply of freshwater. Under sections on heat and power from the sea, fishery engineering, electronics in developing fisheries, radioactivity in the sea, and, above all, on satellite sensing of marine phenomena, the most recent developments aro well covered.

This is an inevitably large but extremely well produced and illustrated book. 'The price does not seem inordinate in view of the wide coverage and the undoubted excellence of most of the contributions, many with references to further information. It will be invaluable in the libraries of universities and of marine institutions of all descriptions.

C. M. YONGE

\section{NEWTS AND SALAMANDERS}

\section{The Tailed Amphibians of Europe}

By J.W. Steward. Pp. 180+13 photographs. (David and Charles: Newton Abbot, January 1970.) 42s.

URODELES (newts, salamanders and their allies) are represented in Europe by nineteen species which constitute $\mathbf{4 0}$ per cent of the total amphibian fauna of the continent. Although not very much is known about the general ecology of these animals, their systematics has been quite fully investigated and so, too, has their frequently complex breeding biology. European newts and salamanders have, however, remained relatively unfamiliar to the non-specialist, partly because of their secretivo habits but also because, until recently, there has been no book which enables them to be easily identified and which reviews what is known of their general biology. Tho appearance in 1968 of R. Thorn's Les Salamandres went some way towards filling this gap, and J.W. Stoward's book attempts to do more or less the same in English. Its text includes descriptions of all the recognized species and subspecies occurring in Europe, and there are notes on habits and breeding. The author also speculates about likely shifts in distribution during the Pleistocene ice ages, but strangely does not mention the possible role of these climate changes in species formation. (It has bocn suggested that various pairs of newt species, for instance the warty and marbled newts, Triturus cristatus and T. marmoratus, arose through the division of the ranges of single ancestral species by glaciation.) The distribution of each form is shown in admirably clear maps and there is a large number of illustrations, chiefly wash-drawings and photographs.

Unfortunately, this book does not provide for the swift identification of specimens, for there is no key and one must laboriously compare descriptions which are not clearly scparated from the rest of the text. The illustra. tions give only limited help because the drawings, while generally recognizable, lack clarity and the nine pages of photographs could have been better used. Of the fourteen photographs no less than six are of Salamandra salamandra, one of the most easily recognized species, which is already illustrated twice elsewhere in the book. The author states that the photographs mostly show the condition outside the breeding season, which would be useful as some newts are not easy to identify at this time, but in actuality at least four of the six photographs showing newts depict breeding specimens.

It is debatable whether in a semi-popular book so much space should have been given over to subspecies, especially because many of them have been raised on relatively trivial features. An introductory note pointing out the essentially subjective nature of this category would have been in order. Notwithstanding these reservations, this book should help popularize an unfairly neglected group of animals.

E. N. ARNOLD

\section{TAXONOMY OF PARASITES}

\section{Problems in Systematics of Parasites}

Edited by Gerald D. Schmidt. (Proceedings of a Symposium held under the auspices of the American Association for the Advancement of Science.) Pp. 131. (University Park Press: Baltimore, Md, and Manchester, September 1969.) $\$ 7.95$.

AT this symposium five specialists reviewed and discussed problems of classification prevailing in their respective fields, for, as the editor explains, disciplines of modern science introduced into taxonomy have produced no revolution in the systematics of parasites.

Professor W. L. Bullock makes clear, in "Morphological Features as Tools and as Pitfalls in Acanthocephalan Systomatics", that the greatly differing opinions found in acanthocephalan classification lie in the misuse of morphological features. Although the division of this phylum into three orders is well founded on basic morphology, the constitution of each order is difficult to comprehend, and it seems desirable to apply, in addition to a closer morphological understanding, data from life-histories, embryology and perhaps biochemistry, to taxonomic concepts of the Acanthocephala.

In "Systematics of Cestodes-Present and Future", Dr Marietta Voge criticizes the use of morphology as the foundation of cestode classification. The possibility of using characters other than morphological in defining and grouping various taxa is discussed, and it is suggested that structural and developmental features of the preadult stages aro more reliable than adult morphology for 